\title{
A OCUPAÇÃO NO ENTORNO DAS TERRAS INDÍGENAS EM RONDÔNIA, BRASIL
}

\author{
THE OCCUPATION IN THE SURROUNDINGS OF INDIGENOUS LANDS IN \\ RONDÔNIA-BRAZIL
}

\section{LA OCUPACIÓN EN LOS ALREDEDORES DE LAS TIERRAS INDÍGENAS EN RONDÔNIA-BRASIL}

\author{
Alex Mota Santos - Universidade Federal de Rondônia - Porto Velho - Rondônia - Brasil \\ alex.geotecnologias@gmail.com
}
Maria Lúcia Cereda Gomide - Universidade Federal de Rondônia - Porto Velho - Rondônia - Brasil malugomide@yahoo.com.br

\section{Resumo}

A ocupação da Amazônia, especialmente em Rondônia, ocasionou a supressão dos territórios indígenas. Assim, parte desses territórios são as atuais terras demarcadas, que em muitos casos, encontram-se pressionadas pelas atividades econômicas que as envolvem. Desta forma, o presente trabalho tem como objetivo mapear e discutir as pressões da ocupação no entorno das Terras Indígenas no Estado de Rondônia. Para alcançar os objetivos propostos, aplicou-se métodos indiretos de análise espacial: análises de imagens de sensoriamento remoto orbital e álgebra de mapas. Os resultados revelaram que a área estudada soma 5.504.717,63 hectares, sendo que 1.438.577,46 estão comprometidos por usos múltiplos, em que destaca a pecuária extensiva. A Terra Indígena (TI) Rio Omerê é, dentre as 21 terras indígenas analisadas, a que apresentou maior valor de área antropizada do entorno próximo, um total de $65,36 \%$, seguida das Terras indígenas Ribeirão e Lage, com 52,56\% e 50,34\%, respectivamente. Por outro lado, o entorno da TI Rio Negro Ocaia apresenta-se mais preservado, com apenas $0,31 \%$ da área desmatada. Além disso, aproximadamente $70 \%$ da área estudada revelou um Índice de Pressão Antrópico (IPA) baixo, enquanto que 3,54\% apresentou IPA Alto. Palavras-chave: Ocupação na Amazônia, Rondônia, Terras Indígenas.

\section{Abstract}

The not indigenous occupation of the Amazon, especially in the Brazilian state of Rondônia, has led to the suppression of indigenous lands. Thus, part of these territories are the current demarcated Indigenous reserves, are often under pressure from the economic activities that surround them. In this context, the purpose of this study is to map and analyze the occupation of the areas surrounding indigenous lands in the state of Rondônia. In order to achieve the objectives, indirect spatial analysis methods, especially using satellite images and map algebra, were applied. The results reveal that the area surrounding all the indigenous lands in the state amounts to $5.504 .717,63$ hectares, considering that $1.438 .577,46$ hectares are employed for multiple uses, especially extensive cattle raising activities. Among the 20 indigenous reserves in Rondônia, the Rio Omerê Indigenous Reserve has the greatest amount of surrounding area that has been developed at $65.36 \%$, followed by the Ribeirão and Lage reservations, at $52.56 \%$ and $50,34 \%$, respectively. On the other hand, the area surrounding the Rio Negro Ocaia reservation is the most intact, with only $0.31 \%$ of the area having been cleared. In addition, approximately $70 \%$ of the total area of around met anthropic pressure index (API) Low, while $3.54 \%$ had API High.

Keywords: Occupation of Amazon, Rondônia State, Indigenous Reserve. 


\section{Resumen}

La ocupación de la Amazonia, especialmente en el estado de Rondônia, resultó en la supresión de los territorios indígenas. De esa manera, parte de estos territorios son las actuales tierras demarcadas, que en muchos casos se encuentran presionadas por las actividades económicas que se desarrollan alrededor de las mismas. Así, este trabajo tiene como objetivo mapear y discutir las presiones de la ocupación alrededor de las Tierras Indígenas demarcadas en el estado de Rondônia. Para alcanzar los objetivos propuestos, se aplicaron métodos indirectos de análisis espacial: análisis de imágenes de teledetección y algebra de mapas. Los resultados revelaron que el área estudiada suma 5.504.717,63 hectáreas, siendo que 1.438.577,46 hectáreas están comprometidas por usos múltiples, destacándose la ganadería extensiva. La Tierra indígena (TI) Rio Omerê es, de entre las 21 tierras indígenas analizadas, la que presentó mayor valor, un total de 65,36\% del área del entorno impactada por actividades antrópicas, seguida de la Tierras Indígenas Ribeirão y Lage, con $52,56 \%$ y $50,34 \%$, respectivamente. Por otro lado, el entorno de la TI Rio Negro Ocaia se presentó más preservada, con solamente $0,31 \%$ del área deforestada. Además de eso, aproximadamente el $70 \%$ de la área estudiada presentado Índice de Presión Antrópica (IPA) bajo, mientras que 3,54\% tenía IPA Alto.

Palabras clave: ocupación de la Amazonia, Rondônia, tierras indígenas.

Introdução

A ocupação não indígena do Estado de Rondônia se consolidou na década de 1970, especialmente com a sua integração à malha viária nacional, em que se destaca a BR-364, e se efetivou com a distribuição de terras ao longo desta rodovia, com expansão das atividades agrícolas, pecuárias, exploração de madeira e mineração (Fearnside, 1980; INPE, 1992; Moran, 1993; Cim, 2003; GTA, 2008).

A consolidação dessa ocupação resultou na intensa retirada da vegetação, que contribuiu para a supressão dos territórios dos povos da floresta e pressão sobre suas terras. Segundo Freitas (2009), a ocupação supracitada nas décadas de 1960 e 1970, tornou-se sobremaneira, um momento de extrema violência física e cultural com as diversas populações indígenas.

A retirada da vegetação em Rondônia teve os maiores picos na década de 1990 e até o ano de 2007 foi maior do que os outros estados da Amazônia (GTA, 2008). Desta forma, observando a data de criação de novos municípios em Rondônia, identifica-se que foi também nesse período que 29, dos atuais 52 municípios foram emancipados, e isso pode ter contribuído para abertura de novas fronteiras agrícolas.

Segundo o INPE (2015), o desmatamento acumulado no estado de Rondônia até o ano de 2014 foi de $88.606,60$ km², o que representou $36,86 \%$ da área total do estado. Segundo Fonseca et al. (2014), em maio de 2014, grande maioria (71\%) do desmatamento na Amazônia Legal 
ocorreu em áreas privadas ou sob diversos estágios de posse. Além disso, segundo os autores, desse total 10\% ocorreram em Rondônia.

Assim, a retirada da vegetação expôs as Terras Indígenas que ocupam 5.0618,38 km², o que corresponde a 21,31\% da área do Estado de Rondônia. Segundo o GTA (2008) as Terras Indígenas neste estado têm sido cada vez mais ameaçadas pelo desmatamento ilegal. Inclusive, segundo Freitas (2009), ocorreram incentivos do Instituto Nacional de Colonização e Reforma Agrária (INCRA) com a distribuição de lotes em Terras Indígenas (TI) em Rondônia.

Destaca-se o fato de que as Terras Indígenas no Brasil não dispõem de definição de áreas de amortecimento como as Unidades de Conservação, que possuem área circundante para amortecimento dos usos no entorno, conforme Decreto $n^{\circ}$. 99.274/90. Contudo, apesar das Terras Indígenas não possuírem uma zona que seria de amortecimento, o Decreto $\mathrm{n}^{\circ}$. 7.747 de 05/05/2012, que instituiu a Política Nacional de Gestão Territorial e Ambiental de Terras Indígenas (PNGATI), revela a necessidade da promoção de ações de prevenção e controle de desastres, danos, catástrofes e emergências ambientais nas Terras Indígenas e entornos, ações de educação ambiental e indigenista no âmbito dessas terras. Nesse sentido, a criação de corredores ecológicos ou etnoambientais entre as TIs é uma forma de minimizar os impactos negativos sobre essas terras (Gomide e Kawakubo, 2005).

Com isso, a análise da ocupação no entorno de TIs no estado de Rondônia é uma tarefa necessária, mas complexa, devido à grande extensão territorial e dificuldades de acesso. Portanto, buscou-se, a partir de imagens orbitais, analisar os usos da terra que se estabelecem nos arredores das TIs e as pressões identificadas.

\section{Procedimentos Metodológicos}

O estado de Rondônia possui 20 TIs, sendo que 17 têm sua localização integral na área dele e três ocupam territórios de Rondônia e Mato Grosso (Figura 1). A TI Zoró, que apesar de estar localizada inteiramente em Mato Grosso, compõe o corredor Tupi-Mondé e se liga às terras de Rondônia e, por isso, foi analisada.

A pesquisa foi sustentada por métodos indiretos de análise do ambiente, em que se destaca o uso de imagens de sensoriamento remoto 
orbital, que tem como principal vantagem a visão sinóptica do meio. Dessa forma, na Amazônia, os usos de imagens orbitais contribuem para a discussão das práticas humanas que comprometem a sociodiversidade regional no tempo e no espaço. Contudo, diversos são os métodos de análise das imagens de sensoriamento remoto.

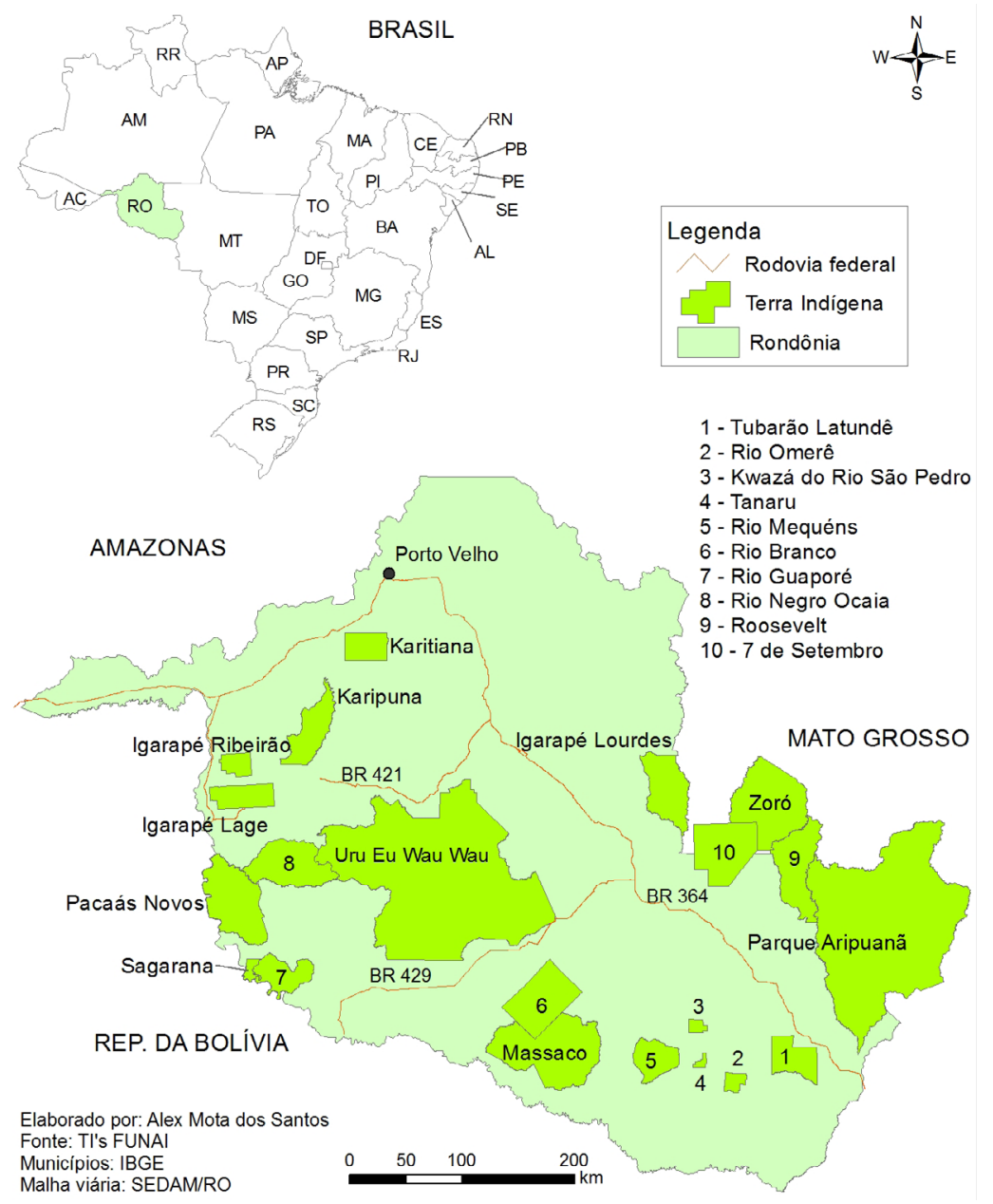

Figura 1 - Localização das Terras Indígenas no Estado de Rondônia, ano 2015 
Segundo Gonzalez e Woods (2000), os procedimentos que envolvem as análises de imagens orbitais podem ser agrupados em quatro etapas básicas, desde a aquisição do dado, sua correção geométrica e radiométrica, passando pelo processamento até a análise dos resultados. Assim, foram adquiridas imagens do LANDSAT8, sensor OLI do período de estiagem do ano de 2013 para se evitar a interferência de nuvens. Com isso, foram necessárias 15 cenas, sendo órbitas-ponto: 001-066; 001-067; 229-067; 229-068; 229-069; 230-067; 230-068; 230-069; 231-067; 231-068; 231-069; 232-066; 232-067; 232-068 e 233-067. As imagens foram corrigidas e processadas no Sistema de Informação Georreferenciada (SPRING) (Câmara et al., 1996), disponíveis gratuitamente pelo Instituto Nacional de Pesquisas Espaciais (INPE).

Nesse sentido, empregou-se o método de classificação por regiões, realizando-se a rotulação da imagem pelo método de segmentação. No SPRING, para o processo de segmentação, é necessário indicar um critério de similaridade para cada par de região adjacente espacialmente. Assim, nesta pesquisa, a similaridade variou devido à grande extensão da área em estudo de 800 a 2000 (não dimensional).

A partir da imagem rotulada, aplicou-se a classificação pelo método supervisionado Battacharya. Segundo Câmara et al. (1996), a medida da distância de Battacharya é usada neste classificador por regiões para medir a separabilidade estatística entre um par de classes espectrais, ou seja, mensura a distância média entre as distribuições de probabilidades de classes espectrais.

Para análise da pressão utilizou-se, além do mapa de uso, dados adicionais que estão descritos na Tabela 1. Além disso, para análise do entorno, calculou-se $10 \mathrm{~km}$ de raio a partir do limite de cada Terra Indígena e foram definidas para o processamento de imagens as classes de uso da terra: agricultura, água, área úmida, cerrado, floresta, ilha fluvial, nuvem, pecuária, queimada, rocha exposta, sombra e urbano, estudadas a partir da observação em campo. Esse valor é sugerido pela legislação das unidades de conservação que não possuem planos de manejo.

Já para análise da pressão antrópica, foi necessário, ainda, estabelecer quais das variáveis analisadas contribuiriam mais para a pressão nas áreas de entorno das TIs. Assim, calculou-se um Índice de Pressão Antrópica (IPA) (Equação 01), derivado do Índice de Transformação Antrópica, desenvolvido por Lémechev (1982) e citado por Mateo (1991). 
Nessa metodologia realiza-se a média da soma das variáveis multiplicadas por seus respectivos pesos.

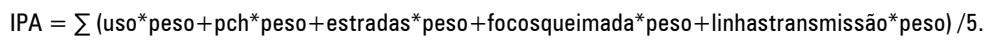

Equação 01: Índice de Pressão Antrópica (IPA).

Fonte: Lémechev (1982) apud Mateo (1991).

Sendo que o peso para cada variável é dado de acordo com o grau de pressão antrópica, que varia de 1 a 10, em que 10 indica pressão máxima. Dessa forma, a determinação dos mesmos levou em consideração as análises dos relatórios do Instituto Socioambiental (ISA) que revelaram quais usos pressionam mais as Terras Indígenas na Amazônia (Carneiro Filho e Souza, 2009).

Os dados tabulados foram submetidos à análise de álgebra de mapas. Dessa forma, os elementos da álgebra de mapas descrita por Tomlin consistem em mapas que associam a cada local de uma dada área de estudo um valor quantitativo (escalar, ordinal, cardinal ou intervalar) ou qualitativo (nominal) (Cordeiro et al., 2007).

Tabela 1 - Pesos dos usos sobre as Terras Indígenas

\begin{tabular}{|c|c|c|c|c|c|}
\hline $\begin{array}{c}\text { Classes de } \\
\text { Uso }\end{array}$ & $\begin{array}{c}\text { Uso/ } \\
\text { Cobertura }\end{array}$ & Fonte & $\begin{array}{c}\text { Classes de } \\
\text { Uso }\end{array}$ & $\begin{array}{c}\text { Uso/ } \\
\text { Cobertura }\end{array}$ & Fonte \\
\hline Agricultura & 10 & Mapa de uso & Queimada & 9,5 & Mapa de uso \\
\hline Água & 1 & Mapa de uso & Rocha exposta & 1,5 & Mapa de uso \\
\hline Área úmida & 1 & Mapa de uso & Sombra & 1 & Mapa de uso \\
\hline Cerrado & 2,5 & Mapa de uso & Urbano & 10 & Mapa de uso \\
\hline Floresta & 1,5 & Mapa de uso & Linha de transmissão & 10 & ANEEL \\
\hline Ilha fluvial & 1,5 & Mapa de uso & Focos de queimada & 10 & INPE \\
\hline Nuvem & 1 & Mapa de uso & Barragens PHC & 10 & ANEEL \\
\hline Pecuária & 10 & Mapa de uso & Estradas & 10 & SEDAM \\
\hline
\end{tabular}

Fonte: Agência Nacional de Energia Elétrica - ANEEL, Secretaria de Estado do Meio Ambiente - SEDAM.

\section{Resultados e Discussões}


Os resultados revelaram que as áreas de entorno de todas as TIs totalizaram 5.504.717,63 hectares, sendo que destas, 1.438.577,46 estavam comprometidas por usos múltiplos. A vegetação predominou no entorno das Terras Indígenas e cobriu 3.740.833,75 hectares, o que correspondeu a $67,95 \%$ da área estudada. A pecuária ocupou 1.178.447,71 e a agricultura $234.654,49$ hectares, o que correspondeu a $21,41 \%$ e $4,26 \%$, respectivamente, do total da área analisada (Tabela 2).

Tanto a pecuária quanto a agricultura são atividades econômicas de alta pressão sobre as TI’s, pois para sua prática, conforme foi observado, é necessária a retirada total da vegetação. Naturalmente, essa prática causa inúmeros impactos, dos quais se destaca a perda de solos e consequente assoreamento dos corpos hídricos.

Tabela 2 - Dado quantitativo das classes de uso na área em estudo

\begin{tabular}{l|l|l}
\hline Classes de Uso & \multicolumn{1}{l}{ Área em hectare } & \multicolumn{1}{l}{$\%$} \\
\hline Agricultura & $234.654,49$ & 4,26 \\
\hline Água & $62.973,48$ & 1,14 \\
\hline Área úmida & $107.290,24$ & 1,95 \\
\hline Cerrado & $162.548,44$ & 2,95 \\
\hline Floresta & $3.578 .285,31$ & 65,00 \\
\hline Ilha fluvial & 461,58 & 0,01 \\
\hline Nuvem & $78.895,39$ & 1,43 \\
\hline Pecuária & $\mathbf{1 . 1 7 8 . 4 4 7 , 7 1}$ & $\mathbf{2 1 , 4 1}$ \\
\hline Queimada & $20.947,95$ & 0,38 \\
\hline Rocha exposta & $13.856,44$ & 0,25 \\
\hline Sombra & $61.829,29$ & 1,12 \\
\hline Urbano & $4.527,31$ & 0,08 \\
\hline Total & $\mathbf{5 . 5 0 4 . 7 1 7 , 6 3}$ & $\mathbf{1 0 0 , 0 0}$ \\
\hline & Fonte: 0 s autores, 2014. &
\end{tabular}

Pelo exposto, tendo em vista que a pecuária foi o uso mais recorrente na área do entorno das Terras Indígenas, recorreu-se aos dados do Instituto Brasileiro de Geografia e Estatística (IBGE) e foi possível constatar que no ano de 1970 havia 23.125 bovinos em Rondônia. Ainda segundo o IBGE (2012), no ano de 2006, o número de bovinos era de 5.064.683, ou seja, houve um aumento de 5.041.558 bovinos em 36 anos. De forma que houve, conforme esses dados apresentados, uma média de aumento de 140.043,23 
bovinos ao ano. Já no ano de 2012 havia 12.218 .437 bovinos, sendo que 9.288.408 foram contabilizados nos municípios onde as Terras Indígenas estão inseridas. Assim, por comparação com o crescimento observado nos 36 anos de consolidação da ocupação em Rondônia, é possível perceber que o número de bovinos de 2006 a 2012 teve um aumento de, em média, 1.192.293,33 bovinos ao ano.

A partir dos dados do IBGE foi possível elaborar o mapa da Figura 02, por meio da qual se observou que os municípios de Porto Velho, em Rondônia e Juína, no Mato Grosso, possuem o maior rebanho bovino e afetam diretamente as TI's Parque do Aripuanã, Karipuna e Karitiana (Figura 2).

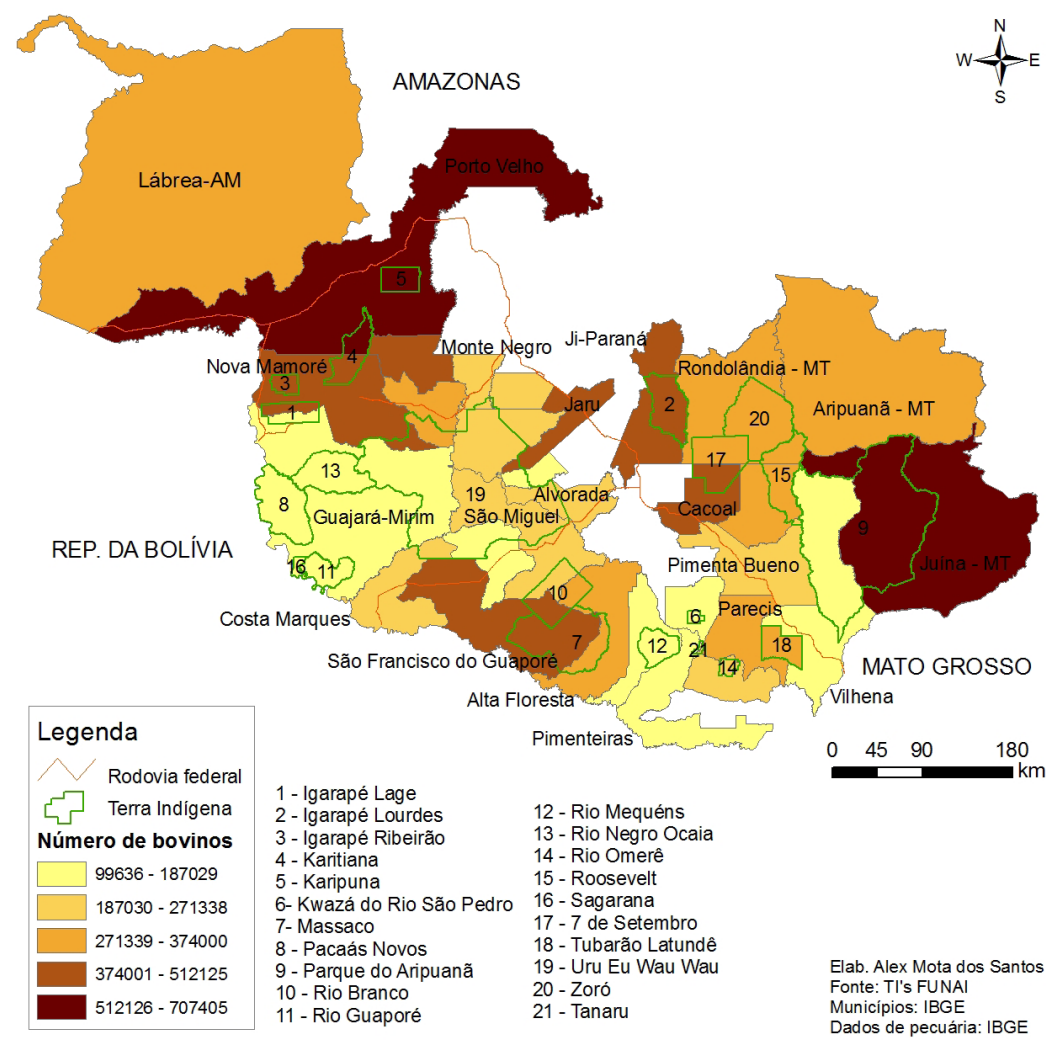

Figura 2 - Quantitativo bovino por município nas áreas de entorno das Terras Indígenas 
Nesse sentido, as maiores áreas ocupadas pela pecuária foram identificadas no entorno das TIs Uru Eu Wau Wau, com área de 292.766,32 hectares; Sete de Setembro com área de 110.700,48 hectares e Igarapé Lourdes, 91.673,41 hectares. Essas Terras Indígenas estão localizadas nos municípios com expressivo rebanho bovino, sendo eles: Nova Mamoré, São Francisco do Guaporé, Jaru, Ji-Paraná, Cacoal, e Monte Negro. Por conseguinte, foi possível identificar também que os municípios com maiores números de bovinos também estão localizados junto à malha viária federal (Figura 2). Além disso, segundo dados do INPE (2014), dos 37 municípios que desmataram mais de $1.000 \mathrm{~km}^{2}$ no ano de 2012, 26 possuem parte de sua área em alguma Terra Indígena. Neste contexto, os municípios de Porto Velho, Ariquemes e Nova Mamoré foram os que

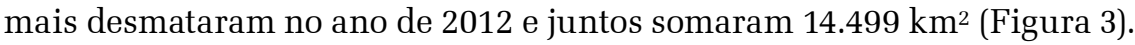

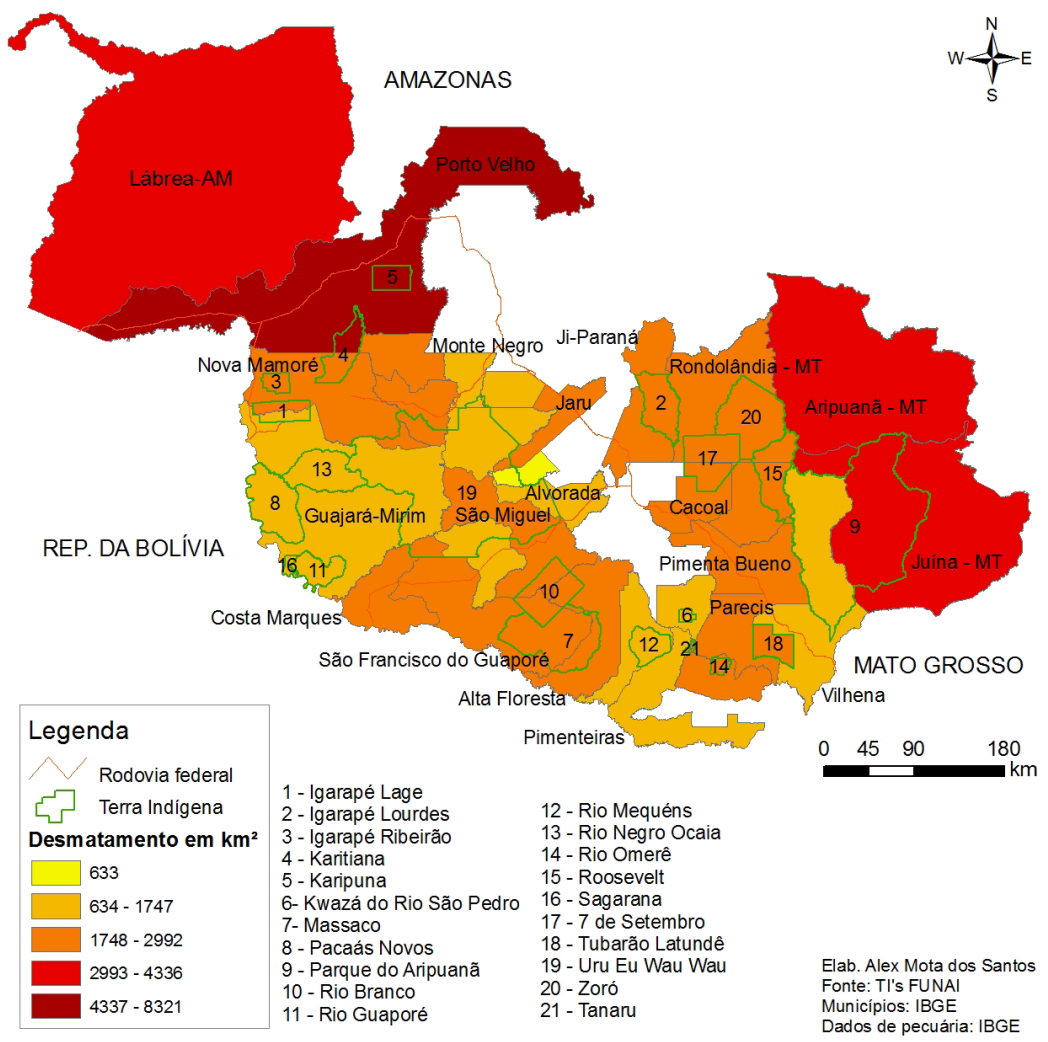


Figura 3 - Desmatamento nos municípios da área de entorno das Terras Indígenas em Rondônia

A área urbana ocupou 4.527,31 hectares e foi caracterizada por pequenos núcleos urbanos, localizados nas áreas do entorno das Terras Indígenas Igarapé Lage, Rio Mequéns, Sete de Setembro, Roosevelt, Tubarão Latundê, Uru Eu Wau Wau e Rio Guaporé.

A Terra Indígena Rio Omerê (Tabela 3) é, dentre as 21 Terras Indígenas analisadas, a que apresentou maior valor de área antropizada, 65,36\% da área do entorno próximo, seguida das TI’s Ribeirão e Lage, com $52,56 \%$ e $50,34 \%$, respectivamente. Na área circunvizinha a TI Rio Omerê, identificou-se 29.938,43 hectares de áreas florestadas, de forma que 40.323,94 hectares já foram convertidos em pecuária e 25.863,08 hectares em agricultura. Portanto, entre os usos da terra, foi a pecuária que apresentou o maior percentual, aproximadamente $40 \%$ do total do entorno. A TI Rio Omerê está localizada nos municípios de Corumbiara e Chupinguaia, que juntos possuem mais de 570 mil bovinos.

Tabela 3 - Representação quantitativa das classes de uso da terra no entorno da TI Rio Omerê

\begin{tabular}{ccc}
\hline TI Rio Omerê & Área em Hectare & $\%$ \\
\hline Agricultura & $25.863,08$ & 25,54 \\
\hline Água & $5.142,42$ & 5,08 \\
\hline Floresta & $29.938,43$ & 29,56 \\
\hline Pecuária & $40.323,94$ & 39,82 \\
\hline Total & $\mathbf{1 0 1 . 2 6 7 , 8 7}$ & $\mathbf{1 0 0 , 0 0}$ \\
\hline
\end{tabular}

Fonte: Os autores, 2014.

A TI Rio Omerê juntamente com as Terras Indígenas Rio Méquens, Kwazá do Rio São Pedro e Tubarão Latundê encontram-se em área de transição do Cerrado-Floresta. Essas áreas em Rondônia estão predominantemente sobre os Neossolos Quartizarênicos, fato que favoreceu a presença de voçorocas que aumentaram a perda de solos nestas áreas.

As voçorocas revelaram as cercas suspensas (Figura 4a), resultado do avanço do ravinamento causado pelos carreadores do gado bovino junto às cercas. As ravinas evoluíram para voçorocas que atingiram 8 metros e 500 metros de comprimento por 10 de largura (Figura 4b). Além 
disso, o solo carreado das voçorocas atinge os rios que drenam para o interior das Terras Indígenas Tubarão Latundê, Rio Omerê, Kwazá do Rio São Pedro e Rio Mequéns. De forma que não se realizou uma análise do material sólido em suspensão nas águas, mas é reconhecido que o aumento no aporte de sedimentos pode contribuir para a colmatação dos rios e igarapés, diminuindo a profundidade, e influenciar negativamente a ictiofauna. Para mais, essas áreas quando convertidas em pastagens e, consequentemente, compactadas, perdem a fertilidade por estarem degradadas, impossibilitando o cultivo agrícola e de pastos, fato que pressiona a retirada da vegetação em outras áreas.

a)

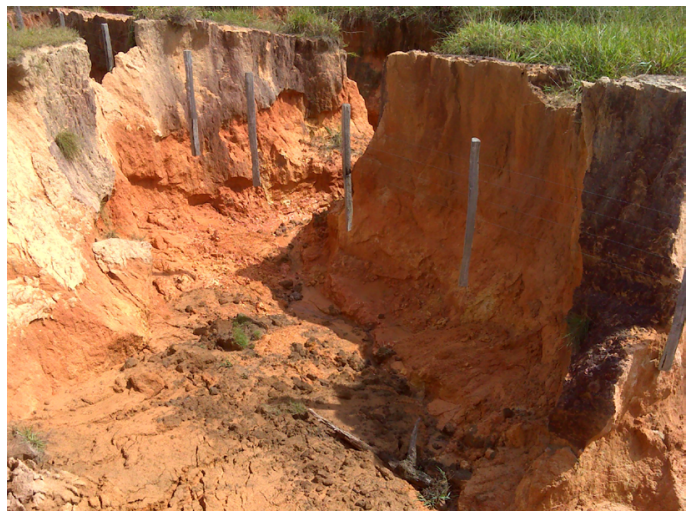

b)

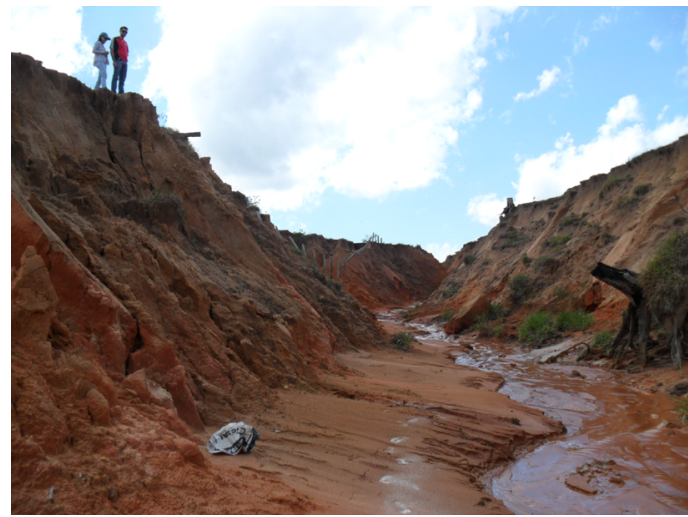

Figura 4 - 4a) Cercas suspensas em área de Neossolos Quartizarênicos e 4b) Voçoroca em Neossolos Quartizarênicos no município de Alto Alegre dos Parecis. Agosto de 2013. 
As áreas de transição estão localizadas sobre relevo de planalto, pouco movimentado, o que facilita a mecanização, também porque os cerrados são facilmente removidos. Com isso, as Terras Indígenas com áreas agrícolas mais extensas no seu entorno, como o Parque do Aripuanã, o Rio Omerê e o Tubarão Latundê, localizadas na porção sudeste de Rondônia, apresentam predominância da agricultura, com extensas monoculturas de grãos, especialmente soja e milho.

Ao contrário das TIs da zona de transição Cerrado-Amazônia, a TI Rio Negro Ocaia, localizada na porção sudoeste (Figura 5), apresentou-se mais preservada, pois apenas $0,31 \%$ da vegetação remanescente foi retirada. As florestas ocuparam 251.852,84 ha, o que correspondeu a $97,65 \%$ da área do entorno e os cerrados, que se caracterizam como enclaves nas florestas, ocuparam $0,74 \%$. A preservação ocorreu nesta área porque no seu entorno identificou-se a Reserva Biológica (REBIO) Ouro Preto e a Reserva Extrativista (RESEX) Pacaás Novos, que são unidades de conservação.

Contudo, o "tempo de sossego" das áreas de entorno da TI Rio Negro Ocaia parece que não durará muito, já que a ideia difundida na década de 1980, de construir uma rodovia (Santos, 2014), está sendo proposta novamente. Nesse sentido, a nova rodovia está planejada para interligar os municípios de Pimenteiras de Rondônia (sul) e Guajará-Mirim (oeste).

Conforme Figura 5, foi possível observar que as Terras Indígenas se encontram dispersas no Estado de Rondônia, isoladas, e apenas duas áreas parcialmente contínuas foram identificadas: o corredor Tupi Mondé, na porção leste, e o corredor Guaporé Mamoré Itinez, na porção sudoeste. No entanto, o corredor Tupi Mondé, apresenta descontinuidades devido à abertura de uma estrada interestadual (Rondônia-Mato Grosso) e consequente abertura de novas ocupações ao longo do eixo desta malha viária. As demais Terras Indígenas não possuem os corredores ecológicos, pois estão isoladas e seus arredores encontram-se ocupados por usos múltiplos.

Ainda a partir da Figura 5, foi possível identificar que a ocupação se consolidou na porção onde se identificou a malha viária federal e estadual, principalmente com a BR-364. Com efeito, ao longo das rodovias federais, a pressão é maior à medida que as mesmas se aproximam das Terras Indígenas. As Terras Indígenas Rio Negro Ocaia, Pacaás Novos, Sagarana e Rio Guaporé estão mais isoladas, distantes da malha viária, portanto, mais afastadas das áreas de ocupação da agropecuária, e por isso, menos pressionadas pela frente de expansão do agronegócio. 
A maior TI do Estado de Rondônia, a Uru Eu Wau Wau apresentou as porções norte, sul e leste alteradas, mantendo a conservação da vegetação de floresta apenas na porção oeste, que faz divisa com a TI Rio Negro Ocaia e Parque Estadual de Guajará-Mirim. A área do entorno da TI Uru Eu Wau Wau ocupou 783.033,10 hectares, dos quais 37,39\% tiveram áreas convertidas para cultivo de gramíneas exóticas para alimento do gado bovino, especialmente a Brachiaria.

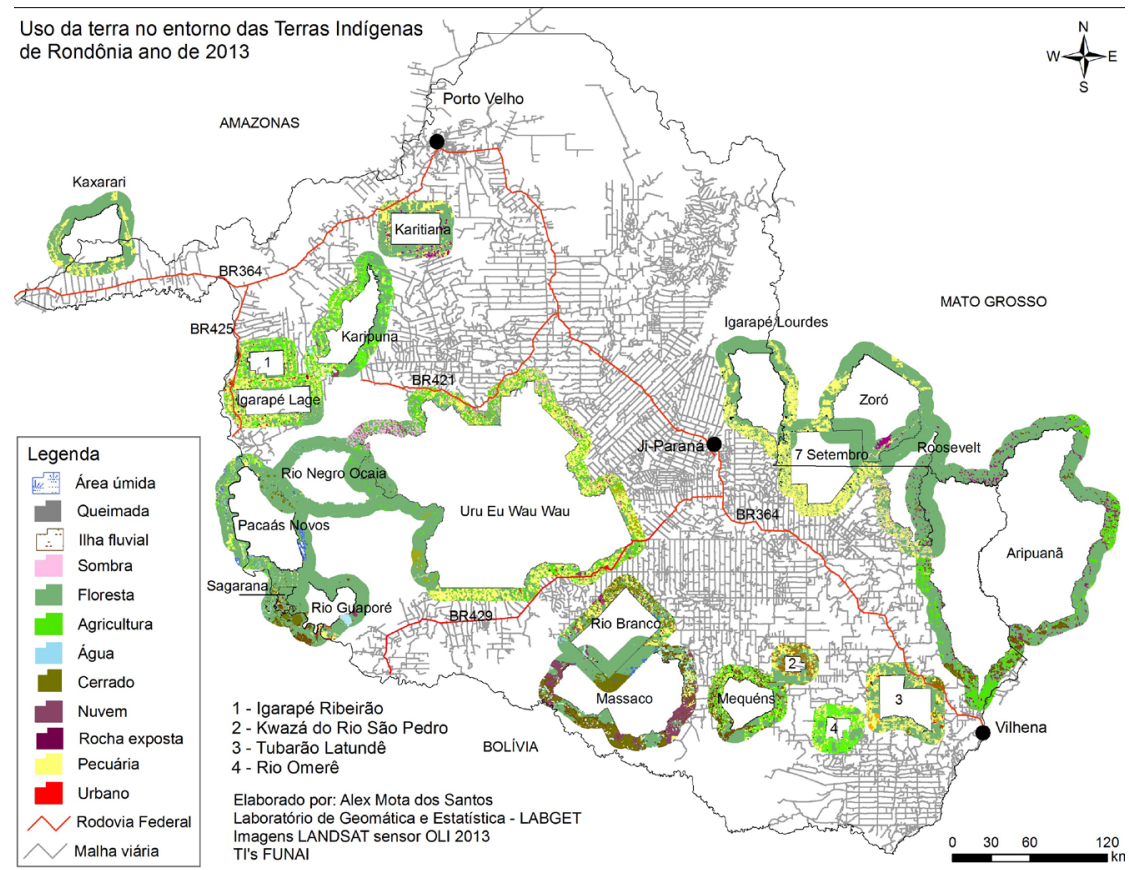

Figura 5 - Ocupação no entorno das Terras Indígenas de Rondônia

A menor TI de Rondônia é a Tanaru, com área de 8.070 ha, contudo encontra-se interdidata (FUNAI, 2014) e não foi alvo de análise de pressão antrópica. Outra terra indígena de área pequena é a Kwazá do Rio São Pedro, localizada na porção Sul de Rondônia. Em relação a sua área de entorno, está bem conservada, com 48,23\% coberta por florestas e 21,42\% coberta por cerrados, sendo que a pecuária ocupou $29,76 \%$ da área de entorno. Assim, a extensão agrícola é pequena, não sendo identificadas expressivas áreas de cultivo nas imagens orbitais de média resolução espacial. 
Igualmente importante é referir que as terras localizadas ao longo do eixo das rodovias federais também estão expostas à presença das principais cidades de Rondônia, Porto Velho, a capital, e a cidade de Ji-Paraná, que possui a segunda maior população do estado, fato que contribui para a exposição das mesmas.

Ao realizar uma análise espacial no entorno da TI Rio Omerê, que como observado foi a mais pressionada, dentre as 21 analisadas, foi possível identificar um cenário preocupante, uma vez que se destacaram áreas ocupadas por pastagem e agricultura, que se limitam com a Terra Indígena (Figura 6).

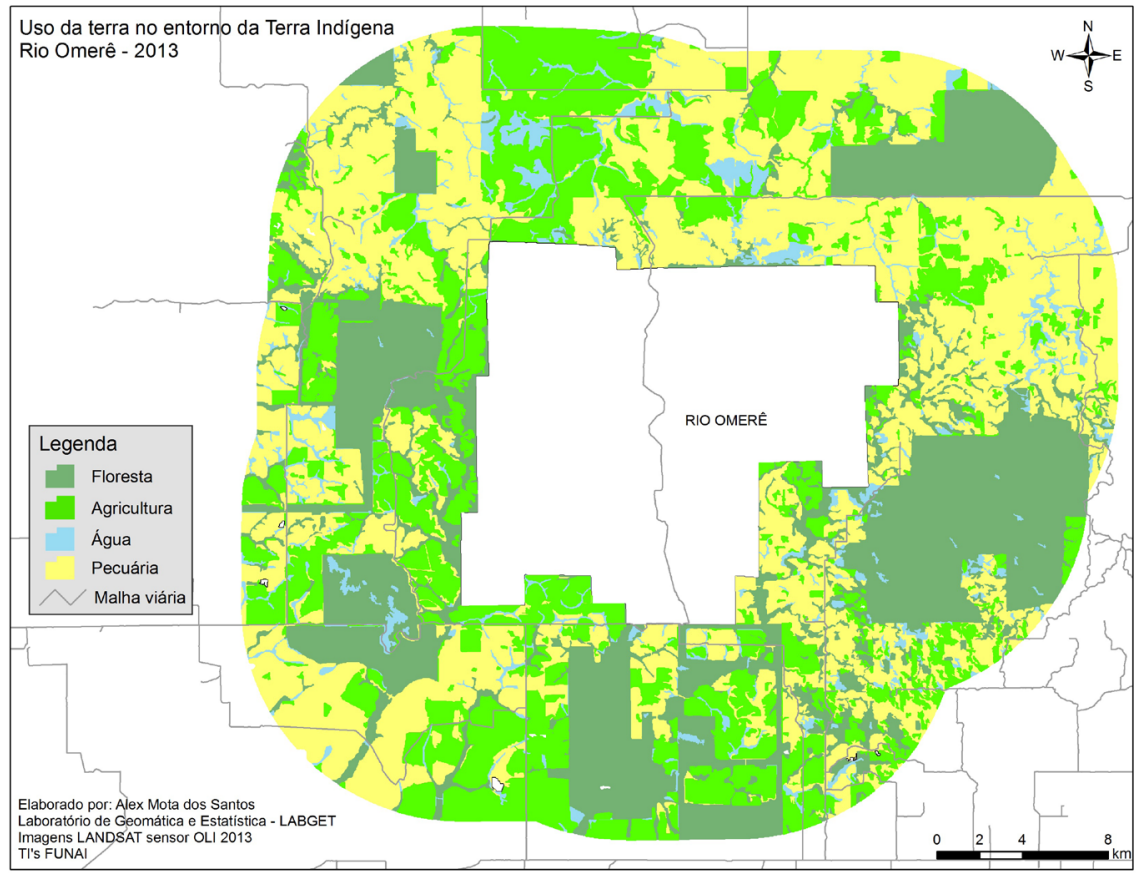

Figura 6 - Ocupação no entorno da TI Rio Omerê

Outros fatores de grande impacto socioambiental são: a rodovia municipal não pavimentada que atravessa a Rio Omerê no sentido norte-sul e as barragens para produção de energia elétrica - pequenas centrais hidrelétricas - fato que explica a vasta área classificada como água no entorno desta TI. 
Além disso, na vegetação remanescente encontrou-se 182 fragmentos, sendo contabilizados 164 menores que um hectare, 15 fragmentos com áreas que variaram de um a dez hectares e somente três fragmentos com áreas superiores a dez hectares. Portanto, a TI Rio Omerê está isolada, embora esteja localizada muito próxima à TI Tubarão Latundê.

Nesse sentido, parte da retirada da vegetação na área da TI Rio Omerê foi reportada pela FUNAI (FUNAI, 2011). Segundo a notícia, um fazendeiro ocupava uma área localizada no interior da TI Rio Omerê, alegando não ter recebido indenização pelas benfeitorias na propriedade. Assim, o fazendeiro conseguiu da Secretaria Estadual de Meio Ambiente (SEDAM) uma licença ambiental e autorização para exploração da floresta. Contudo, o Ministério Público anulou a licença e concedeu liminar para suspender os efeitos da autorização.

\section{Análise da Pressão Antrópica}

A partir das variáveis definidas para o estudo da pressão sobre as Terras Indígenas de Rondônia, identificou-se que aproximadamente 70\% da área total do entorno encontram-se com Índice de Pressão Antrópico (IPA) baixo, já 3,54\% apresentaram IPA alto e 0,21\%, muito alto (Tabela 4).

Tabela 4 - Dados quantitativos do IPA no entorno das Terras Indígenas em Rondônia

\begin{tabular}{cccc}
\hline Nível & IPA & Área em ha & $\%$ \\
\hline Baixo & $1-2,7$ & $3.748 .852,55$ & 69,06 \\
\hline Moderado & $2,8-4,5$ & $1.476 .082,30$ & 27,19 \\
\hline Alto & $4,6-6,3$ & $192.047,64$ & 3,54 \\
\hline Muito Alto & $6,4-8,1$ & $11.151,15$ & 0,21 \\
\hline Total & $\mathbf{1}$ a 10 & $\mathbf{5 . 4 2 8 . 1 3 3 , 6 4}$ & $\mathbf{1 0 0}$ \\
\hline
\end{tabular}

Fonte: Os autores, 2014.

Os resultados confirmaram que as TIs de fácil acesso pela malha viária são aquelas com IPA mais alto. Esse dado revelou que a malha viária, ao expor as Terras Indígenas ao acesso indiscriminado, contribuiu para sua pressão antrópica não indígena, uma vez que as estradas são construídas por ordem do Governo do Estado, fato que explica muito 
sobre os atores responsáveis pelas pressões sobre as Terras Indígenas em Rondônia. Assim, há que se concordar com Mello (2003), quando o mesmo afirma que o Estado ainda tem papel de destaque no incentivo à ocupação de Rondônia.

Além disso, observou-se que das TIs analisadas, 16 apresentaram IPA alto e as TI's Uru Eu Wau Wau e Sete de Setembro apresentaram áreas com IPA muito alto (Figura 7).

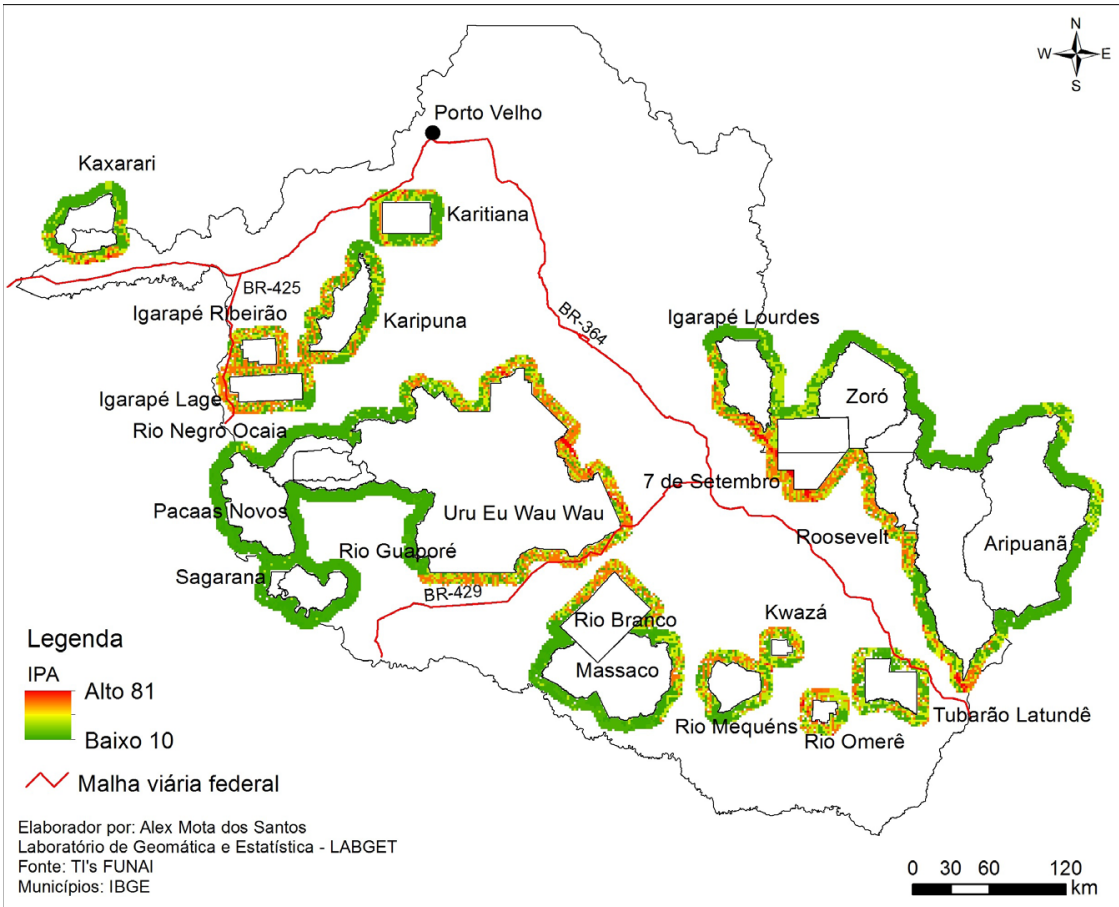

Figura 7 - Índice de Pressão Antrópica no entorno das Terras Indígenas em Rondônia

Nesse sentido, há que se concordar com Mello (2003) que o Estado Nacional destaca-se no incentivo da ocupação na Amazônia. Dessa forma, o Estado Nacional, por meio dos seus bancos, também financia inúmeras fazendas de pecuária no entorno das Terras Indígenas em Rondônia e levam à concentração da matriz econômica sobre essa atividade. Assim, ao facilitar o crédito para criação de gado bovino, produção de energia e agricultura o Estado está favorecendo a conversão das paisagens de Rondônia. 
Outro fator a se discutir são as pequenas centrais hidrelétricas, que se espalharam rapidamente pelos rios de Rondônia e são motivo de reclamações de diversos povos indígenas que alegam que tais práticas contribuem para a alteração do ciclo migratório de peixes e quelônios (Santos, 2014). Essas alterações foram reveladas por Santos (1995), quando o autor observou que algumas espécies da ictiofauna muito frequentes no período de pré-enchimento não apareceram no período de pós-enchimento do reservatório de Samuel em Rondônia. Ainda de acordo com a pesquisa de Santos (1995), algumas espécies se mantiveram, mas em porcentagem reduzida, ao passo que outras aumentaram significativamente, contribuindo para o desequilíbrio ambiental.

Após a discussão em tela, propõe-se que no entorno das terras indígenas sejam criadas áreas de amortecimento e corredores ecológicos, sendo que esses podem ser implantados a partir das áreas de proteção permanente, nas beiras dos rios e reservas legais. Desta forma, teríamos menores impactos negativos incidindo nas terras indígenas, assegurando aos povos indígenas sua sobrevivência física e cultural.

\section{Considerações finais}

A discussão sobre os usos múltiplos no entorno das Terras Indígenas é necessária e urgente num contexto de ataques claros aos direitos dos indígenas no Brasil. Assim, o que se viu em Rondônia foi a predominância da retirada da vegetação nas áreas de entorno para cultivo de gramíneas exóticas destinadas à criação de gado bovino e agricultura de grãos no sudeste do Estado. Além disso, apesar da presença da vegetação, no entorno de algumas Terras Indígenas, a mesma encontra-se fragmentada. E assim, observou-se que muitas terras estão isoladas pelas práticas agropecuárias nas áreas que deveriam ser conectadas por corredores.

Nesse sentido, as Terras Indígenas localizadas junto à malha viária mais estruturada estão mais pressionadas, já que estão expostas à circulação indiscriminada da sociedade envolvente. Ao contrário, identificou-se que as Terras Indígenas localizadas nas proximidades de unidades de conservação e afastadas da malha viária estão mais preservadas, favorecendo corredores ecológicos. Por consequência, as pressões são mais significativas nas Terras Indígenas inseridas na área de intensa ocupação junto ao eixo das rodovias federais, especialmente a BR-364, BR-425 e BR-429. 
Por todo o exposto, é possível considerar que a ocupação e o aumento da pressão do entorno contribui para a exposição dos povos indígenas e dos seus modos de vida. Além disso, expõe os recursos naturais de suas terras que se tornam escassos, portanto, de difícil acesso as comunidades indígenas. Com efeito, espera-se com este trabalho ampliar as discussões acerca da ocupação e pressões no entorno das Terras Indígenas em Rondônia. Por fim, defende-se que se torne uma política pública a implantação do PNGATI e a garantia das áreas de entorno como zonas de amortecimento das TIs de todo o país.

\section{Referências}

BRASIL, Decreto $\mathrm{n}^{\circ}$ 99.274, de 6 de Junho de 1990. Criação de Estações Ecológicas e Áreas de Proteção Ambiental e sobre a Política Nacional do Meio Ambiente. Disponível em: <http://www.planalto.gov.br/ccivil_03/decreto/ antigos/d99274.htm>. Acesso em: 13 out. 2014.

; Decreto no 7.747, de 5 de Junho de 2012. Política Nacional de Gestão Territorial e Ambiental de Terras Indígenas - PNGATI. Diário Oficial da União, Brasília, 05 Jun., 2012. Disponível em: <http://www.planalto.gov.br/ ccivil_03/_ato2011-2014/2012/decreto/d7747.htm>. Acesso em: 13 out. 2014.

CARNEIRO FILHO, A; SOUZA, O. B. Atlas de pressões e ameaças às terras indígenas na Amazônia brasileira. São Paulo: Instituto Socioambiental, 2009.

CÂMARA, G.; SOUZA, R.C.M.; FREITAS, U.M.; GARRIDO, J. Integrating remote sensing and GIS by object-oriented data modelling. Computers $\&$ Graphics, v. 20, n. 3, p. 395-403, 1996.

CIM, S. O processo migratório de ocupação no estado de Rondônia - visão histórica. Revista Primeira Versão, n. 104, 2003. Disponível em: <http://www. primeiraversao.unir.br/atigos_pdf/numero104Cinn.pdf $>$. Acesso em: 12 ago. 2012.

CORDEIRO, J.P.; BARBOSA, C.C.F. CÂMARA, G. Álgebra de Campos e objetos. In: CÂMARA, G.; MONTEIRO, A.M.; DAVIS, C. Geoprocessamento: Teoria e Aplicações, 2007. Disponível em: <http://www.dpi.inpe.br/gilberto/livro/>. Acesso em: 13 ago. 2011.

FREITAS, E. B. Índios de Rondônia. Vozes da (des) integração e Imaginário da sobrevivência. ANPUH - XXV Simpósio Nacional de História. Anais. Fortaleza, 2009.

FEARNSIDE, P. M. Os efeitos das pastagens sobre a fertilidade do solo na Amazônia Brasileira: consquências para a sustentabilidade de produção bovina. Acta Amazônica, v. 10, p. 119-132, 1980.

FONSECA, A.; MARTINS, H.; SOUZA JÚNIOR, C.; VERÍSSIMO, A. Transparência Florestal. Amazônia Legal. Imazon, 2014. 
FUNAI (Fundação Nacional do Índio). Arquivos vetoriais das terras indígenas. Mapas. Disponível em: <http://mapas.funai.gov.br/>. Acesso em: 11 dez. 2014.

Procuradoria impede exploração florestal ilegal na Terra Indígena Rio Omerê, em Rondônia. 2011. Disponível em: <http://www.funai.gov.br/index. $\mathrm{php} / \mathrm{comunicacao} /$ noticias/2018-procuradoria-impede-exploracao-florestalilegal-na-terra-indigena-rio-omere-em-rondonia >. Acesso em: 11 jun. 2014.

GOMIDE, M. L.C.; KAWAKUBO, F. S . Povos indígenas do cerrado, territórios ameaçados: terras indígenas Xavante de Sangradouro/ Volta Grande e São Marcos. In : Revista Agrária, Agrária (São Paulo. Online), [S.l.], n. 3, p. 1646, dez. 2005. Disponível em: <http://www.revistas.usp.br/agraria/article/ view/86>. Acesso em: 05 dez. 2013. DOI: http://dx.doi.org/10.11606/issn.18081150.v0i3p16-46.

GONZALEZ, R. C.; WOODS, R. E. Processamento de Imagens Digitais. São Paulo: Edgard Blucher, 2000. 509 p.

GTA (GRUPO DE TRABALHO AMAZÔNICO). A Devastação das Unidades de Conservação e Terras Indígenas no Estado de Rondônia. 2008. Disponível em: <http://www.kaninde.org.br/upload/2012/04/o_fim_da_floresta_1333816947. pdf.> Acesso em: 22 maio 2013.

IBGE (INSTITUTO BRASILEIRO DE GEOGRAFIA E ESTATÍSTICA). Instituto Brasileiro de Geografia e Estatística. Censo agropecuário, 2006.

Geociências. Mapeamento das Unidades Territoriais. Produtos. Arquivos vetoriais, 2007. Disponível em: <ftp://geoftp.ibge.gov.br/malhas_digitais/ censo_2007/setor_rural/>. Acesso em: 12 maio 2014.

. Produção da pecuária municipal. 2012. Disponível em: <ftp://ftp.ibge. gov.br/Producao_Pecuaria/Producao_da_Pecuaria_Municipal/2012/ppm2012. pdf.> Acesso em: 24 jun. 2014.

INPE (INSTITUTO NACIONAL DE PESQUISAS ESPACIAIS). Deforestation in Brazilian Amazonia. São José dos Campos, 1992.

Desmatamento nos Municípios. Estado de Rondônia. Disponível em: <http://www.dpi.inpe.br/prodesdigital/prodesmunicipal.php>. Acesso em: 25 ago. 2015.

Taxas anuais do desmatamento - 1988 até 2013. São Jose dos Campos, 2014. Disponível em:< http://www.obt.inpe.br/prodes/prodes_1988_2013. htm>. Acesso em: 7 jun. 2014.

LANDSAT (LAND REMOTE SENSING SATELLITE). Disponível em: < http:// glovis.usgs.gov/>. Acesso em: 11 jun. 2014.

LINHARES, J. S. Geotecnologias aplicadas à análise da dinâmica de ocupação e da vulnerabilidade natural à perda de solos no município de Alto Alegre dos Parecis - Rondônia. (Trabalho de conclusão do curso de Engenharia Ambiental). Universidade Federal de Rondônia, Ji-Paraná, 2013.

MATEO, J. Geoecologia de los Paisajes. Universidad Central de Caracas, Caracas, 1991. 
MELLO, N. A. Contradições Territoriais: signos do modelo aplicado na Amazônia. Sociedade e Estado, Brasília, v. 18, n. 1/2, p. 315-338, jan./dez. 2003.

MORAN, E. F. "Deforestation and Land Use in the Brazilian Amazon”. Human Ecology, v. 21, n. 1, p. 1-21, 1993.

SANTOS, G. M. Impactos da hidrelétrica de Samuel sobre as comunidades de peixes do rio Jamari (Rondônia Brasil). Acta Amazonica, v. 25, n. 3/4, p. 247-280, 1995. Disponível em: <http:/acta.inpa.gov.br/fasciculos/25-4/PDF/v25n4a09. pdf. >. Acesso em: 13 maio 2013.

SANTOS, A.M. Cartografia dos povos e das terras indígenas em Rondônia. Tese (Doutorado) - Setor Ciências da Terra, Departamento de Geografia, Programa Mestrado e Doutorado em Geografia, Universidade Federal do Paraná, Curitiba, 2014.

Alex Mota Santos - Possui Graduação em Sensoriamento Remoto pelo Instituto Federal de Educação, Ciência e Tecnologia de Goiás. Possui Mestrado em Geografia pela Universidade Federal de Goiás. Doutorado em Geografia pela Universidade Federal do Paraná. Atualmente é professor da Universidade Federal de Rondônia.

Maria Lúcia Cereda Gomide - Possui Graduação, Mestrado e Doutorado em Geografia pela Universidade de São Paulo. Atualmente é professora da Universidade Federal de Rondônia.

Recebido para publicação em 12 de agosto de 2015 Aceito para publicação em 5 de outubro de 2015 